\title{
AN AMATEUR NATURALIST'S GUIDE TO NON-BITING MIDGES IN SASKATCHEWAN
}

\author{
P. G. MASON, Agriculture Canada, Research Station, 107 Science Place, Saskatoon, \\ Saskatchewan. S7N 0X2; D. W. PARKER and P. MORRILL, Department of \\ Biology, University of Saskatchewan, Saskatoon, Saskatchewan. S7N 0W0
}

Non-biting midges (chironomids) belong to the insect order Diptera (true flies). Their life cycle consists of four stages: egg, larva, pupa and adult.

The larvae and pupae of chironomids inhabit almost every aquatic habitat in the world. Some species can withstand temperatures in excess of $50^{\circ} \mathrm{C}$ in Australian rockpools, while others inhabit glacial meltwaters at $0.5^{\circ} \mathrm{C} .^{18,19}$ In Canada, chironomids have been found living in petroleum pools and one species, Cricotopus ornatus Meigen, occurs abundantly in Waldsea Lake, Saskatchewan, where salinity exceeds $200,000 \mathrm{ppm}$ (ten times the salinity of ocean water). ${ }^{38,42}$ Many species, particularly in the genera Chironomus and Cryptochironomus, have a characteristic red colour because their blood (hemolymph) contains the oxygen carrying pigment haemoglobin. These socalled "blood worms" live in the mud where oxygen levels are very low, such as at the bottom of Waskesiu Lake. ${ }^{36}$

Some chironomid species form close relationships with other organisms. For example, certain species of Cricotopus live within colonies of the blue-green alga Nostoc. ${ }^{6}$ Species of the genus Metriocnemus live in pitcher plants. ${ }^{34}$ Many other species exhibit phoresy, a type of relationship in which one organism is carried on the body of a larger organism but does not feed on the latter, or parasitize other invertebrates, includ- ing other aquatic insects and mol-
luscs.

Chironomid larvae form an important part of many aquatic ecosystems. In Tobin Lake and nearby parts of the Saskatchewan River, two-thirds of the aquatic insect species are chironomids. ${ }^{27}$ Chironomids also form the bulk of the aquatic insect species in marshes and ponds. ${ }^{17,50}$ Larvae in some nutrient-rich habitats occur in densities of more than $100,000 / \mathrm{m}^{2}{ }^{20}$

The larvae of most species feed on algae and decaying plant material and therefore provide primary links in aquatic food webs. They are also important indicators of pollution at sublethal and lethal levels. ${ }^{29,45,46}$

Chironomids are economically important in many parts of the world. Larvae of one semi-terrestrial species, Bryophaenocladius furcatus (Kieffer) are known to cause damage to seedling tomato and lettuce crops in England. ${ }^{9}$ In certain parts of Florida and California, large emergences of adult chironomids cause reduced use of recreational areas. ${ }^{2,7,22}$ In many areas people suffer from allergenic responses to either body hairs or haemoglobin of chironomid adults. ${ }^{10}$ In Saskatchewan, summer mass emergences of adult Chironomus plumosus (Linnaeus) at Tobin Lake have resulted in many complaints by local residents. 
The objectives of this article are to provide the reader with some background information on these ecologically important insects and to list the species which have been recorded in Saskatchewan.

\section{Life History}

During the spring or summer the female deposits a mass of eggs embedded in a gelatinous matrix. When the egg matrix comes in contact with water, it expands and floats on the surface until it contacts a rock, vegetation or other solid surface, to which it adheres. The duration of the egg stage depends on the temperature. 31

The larval stage is the longest of the life cycle and is essentially the only feeding stage. The larva sheds its skin (moults) four times. The first instar larva (the larva from the time of hatching until the first moult) is free-swimming which is important for dispersal in lakes and ponds. ${ }^{12}$ In rivers and streams, dispersal is accomplished by drifting with the current or by upstream movement by the larvae. ${ }^{13}$ First instar larvae obtain nourishment from the remaining yolk and by feeding on suspended particles in the water. ${ }^{1,30}$

When a suitable microhabitat is found, the larvae establish either a sedentary or free-living mode of life, which continues throughout the rest of larval development. Many sedentary species construct cases composed of particles of silt or sand cemented together with silk-like secretions from their salivary glands. Some species attach their cases to plants or animals while others make burrows a fiw centimetres into the substrate. Freeliving larvae move over the bottom and skim plants in search of food. Many larvae feed be scraping algae, bacteria and organic debris from rocks or wood, or by engulfing quantities of sediment. ${ }^{44,51}$ The larvae of other species construct a net of silk-like salivary strands over the open- ing of their larval case or burrow and filter particles such as bacteria, detritus and algae from the water.

Species of the subfamily Tanypodinae and a few species from other subfamilies are predators. ${ }^{3}$ The mouthparts of these larvae are modified to grasp prey. Small prey are engulfed whole; larger prey are held while the body fluids are sucked out. $^{28}$ A few species are parasitic on larger aquatic insects and molluscs. ${ }^{41}$

The length of time required to complete the life cycle depends on environmental conditions, especially temperature. ${ }^{30}$ In warm regions, life cycles can be as short as two weeks. ${ }^{43}$ In temperate regions, such as Saskatchewan, there are usually only one or two generations per year because development is interrupted during winter. ${ }^{31}$ In these regions the larvae are the usual overwintering stage.

Just before pupation the anterior part of the larva becomes enlarged and the adult leg, wing and antennae can be observed through the sheath during this stage. Pupation of burrow-dwelling chironomids usually occurs within the burrow. In free-living species the pupa is also free-living. The pupal stage typically lasts two to three days. ${ }^{5,31}$

When mature, the pupa rises to the water surface; the skin, which is also an exoskeleton, splits lengthwise long the upper surface of the thorax; the adult emerges through this split. The adult is able to fly almost immediately. The adult stage may last for several weeks; its primary functions are dispersal and reproduction. The adults have reduced mouth parts and most do not feed, although adult females of some species imbibe nectar. ${ }^{16}$

Most chironomid species form mating swarms comprised of adult males. ${ }^{21}$ On a warm, calm summer evening, chironomid swarms commonly appear just before sunset at the edge of lakes. 
The mass of hundreds of individuals gently moves up and down, similar to smoke rising from a smokestack. The swarms occur over a marker, such as a post or rock. Females are attracted to the swarm and fly into it in search of a mate. Mating can take place in midair or the pair may fly to the ground. Male chironomids identified by their long, plumose (feathery) antennae are attracted to the sound of females in flight. ${ }^{35}$

After mating the females fly to oviposition sites where the egg masses are laid on the water surface at dawn or dusk. Adults may live for up to two weeks and the females of some species lay two egg masses. A few species can lay eggs without mating. ${ }^{30}$

\section{Collection and Preservation of Specimens}

Egg masses may be collected from floating sticks or vegetation. A trap can be made by passing a string through a series of corks, arranged perpendicular to the prevailing winds or current to collect floating egg masses.

Larval and pupal specimens can be collected by several methods. A simple method involves scooping substrate from the bottom of a water body with a net or kitchen screen and washing the contents using a sweeping motion to remove fine silt particles from the sample. The contents are placed in a white pan partially filled with water. Live specimens are removed with a wire loop, dropper or forceps and either placed in jars for transport to the laboratory for rearing or preserved in $80 \%$ alcohol.

Larvae of some species are found in specialized habitats such as rotting wood, sponges, plant material or on rocks. These can be searched individually for larvae and pupae.

Pupal skins, which are shed when the adults emerge, can be collected using a fine mesh net. In running water, the net is held in the current for a few minutes with half the opening below the water surface; in lakes or ponds the net is skimmed over the surface. The accumulated individuals are washed to the bottom of the net and the contents placed in a jar containing $80 \%$ alcohol. Foam along the shore of streams, lakes or ponds can also yield specimens.

Dusk is a particularly good time to collect adult specimens using an aerial sweep net. Males are attracted also to lights at night. Specimens are aspirated into a vial and preserved in 70\% alcohol.

A label with the location, habitat type, approximate water depth, date and name of the collector should be placed on each sample. Labels should always be written in pencil.

\section{Rearing}

For many species of chironomids the larval, pupal and adult stages are known independently of each other and have yet to be associated. Rearing larvae to the adult stage is the best means to fill this important gap in our knowledge. Larvae can be reared with little or no specialized equipment. Prepupal individuals, identified by the enlarged area just behind the head, are placed in small vials half full of dechlorinated water (this is done using an aquarium dechlorinator or by letting the water stand for $24 \mathrm{~h}$ ). The vials are placed in a tray of water out of direct sunlight. Tap water $\left(15^{\circ} \mathrm{C}\right)$ can then be circulated through the tray using rubber hoses to keep the larvae cool if temperatures get much above $22^{\circ} \mathrm{C}$. Vials should be checked daily and emerged adults placed in dry vials in a cold $\left(5^{\circ} \mathrm{C}\right)$ refrigerator for $24 \mathrm{~h}$. This hardens the cuticle and ensures that the wings are completely expanded and cleared, which is essential for identification. The adult is then preserved along with the associated larval and pupal 
exuviae in $70 \%$ alcohol.

\section{Preparation of Study Material}

Identification to species or genus requires examination under a microscope. The preparation of specimens for microscopic analysis involves a number of chemicals and equipment not readily available to most naturalists. Interested individuals should refer to Mason, Pinder or Parker for a full account of the procedures used. $^{23,33,35}$

\section{Species List}

The chironomid fauna of Saskatchewan is not very well known. To date, only parts of the Saskatchewan River, Waskesiu and Waldsea Lakes, and ponds in the vicinity of Saskatoon have been studied. Four new species have been described and several other new species have yet to be described from material collected at these sites. ${ }^{25}$ The chironomid fauna of the lakes and streams in and around Lake Athabasca, the boreal forest, Grasslands National Park and the Cypress Hills have yet to be studied. When these areas are studied many species not yet recorded for the province and even new species will likely become known. A list of chironomid species known to occur in Saskatchewan is presented in Table 1 (see end of article). The list is a summary of various works containing new records and significant range extensions for some species. ${ }^{17,23,24,29,33,50}$

\section{Taxonomic Information}

Lists of described genera and North American species are available. ${ }^{4,9}$ Larval keys to genus are presented by Coffman and Ferrington, Oliver and Roussel and Wiederholm. ${ }^{8,32,47}$ Pupal keys for genera are found in Coffman and Ferrington and Wiederholm. ${ }^{8,48}$ Keys to genera for adult males are found in Oliver and Wiederholm and to adult females in Saether. ${ }^{31,39,49}$ Saether provided a glossary for the structural terms of all chironomid stages.
Species keys for known Saskatchewan River chironomids were written by Mason and for pond chironomids by Parker. $23,24,33$ Another useful key is Roback for adult male Tanypodinae.

An analysis of the origin and distribution of Saskatchewan River chironomids is found in Mason and Lehmkuhl. ${ }^{26}$

\section{Areas for Further Research}

This group of insects provides a good opportunity for naturalists to contribute valuable scientific information. For example, a great deal of work is needed in associating larval, pupal and adult stages. Basic survey work is also needed in many parts of the province. Times of emergences are unknown for many species.

\section{References}

1. ALEKSEYEV, N.K. 1965. Plankton feeding of Chironomidae during the larval stage. Nauchnye Poklady U Ysshei Shkoly, Bioligichiskie Nauki 1:19-21.

2. ALI, A. 1981. Laboratory evaluation of organophosphates and new synthetic pyrethroid insecticides against pestiferous chironomid midges of central Florida. Mosquito News 42:157-161.

3. ARMITAGE, P.D. 1968. Some notes on the food of chironomid larvae of a shallow woodland lake in south Finland. Annales Zoologische Fennici 5:6-13.

4. ASHE, P. 1983. A catalogue of chironomid genera and subgenera of the world including synonyms (Diptera: Chironomidae). Entomologica Scandinavica, Supplement 20:1-68.

5. BEATTIE, D.M. 1978. Life cycle and changes in carbohydrate, proteins and lipids of Pentapedilum incinatum Goet. (Diptera: Chironomidae). Freshwater Biology 8:109-113.

6. BROCK, E.M. 1960. Mutualism between the midge Cricotopus and the alga Nostoc. Ecology 41:474-483.

7. BURRILL. A.C. 1913. Economic and biological notes on the giant midge Chironomus (Tendipes) plumosus Meigen. Bulletin of the Wisconsin Nat. Hist. Soc. 10:124-163.

8. COFFMAN, W.P. and L.C. FERRINGTON. 1984. Chapter 25. Chironomidae. Pp. 551-562 in Merritt, 
R.W. and K. W. Cummins (editors), Aquatic Insects of North America. Kendall Hunt, Dubuque, Iowa. 722 pp.

9. CRANSTON, P. S. 1987. A non-biting midge (Diptera: Chironomidae) of horticultural significance. Bull. of Ent. Res. $77: 661-667$.

10. CRANSTON, P.S., M.O. GAD, E. RAB and A.B. KAY. 1981. Chironomid midges as a cause of allergy in the Sudan. Transactions of the Royal Soc. of Tropical Medicine and Hygiene 75:1-4.

11.DANKS, H.V. 1971 a. Overwintering of some north temperate and arctic Chironomidae. Can. Entomol. 103:589604.

12. —_ 1971 b. Life history and biology of Einfeldia synchrona (Diptera: Chironomidae). Can. Entomol. 103:1579-1606.

13.DAVIES, B.R. 1976. The dispersal of Chironomidae larvae: a review. $J$. of the Entol. Soc. of South Africa 39:39-62.

14. DOSDALL, L.M. and P.G. MASON. 1981. A chironomid (Nanocladius (Plecoptera- coluthus) branchicolus: Diptera) phoretic on a stonefly (Acroneuria lycorius: Plecoptera) in Saskatchewan. Can. Entomol. 113: 141-147.

15.DOSDALL, L.M., P.G. MASON and D.M. LEHKUHL. 1986. First records of phoretic Chironomidae (Diptera) associated with nymphs of Pteronarcys dorsata (Say) (Plectoptera: Pteronarcyidae). Can. Entomol. 118:511-515.

16. DOWNES, J.A. 1974. The feeding habits of adult Chironomidae. Entomologia Tidskrift, Supplement 95:84-90.

17. DRIVER, E.A. 1977. Chironomid communities in small prairie ponds: some characteristics and controls. Freshwater Biology 7:121-134.

18. DUMBLETON. L.J. 1973. An ice chironomid. New Zealand Ent. 5:131-133.

19. EDWARD, D.H. 1968. Chironomidae in temporary freshwater. Australian Society of Limnology 6:3-5.

20. FAGAN, C.B. and W.R. ENNS. 1966. The distribution and biology of aquatic midges in Missouri lagoons. Proc. of the Entomol. Soc. of Washington 68:277-289.

21. GIBSON, N.E.H. and L. LLOYD. 1945. On mating swarms of certain Chironomidae (Diptera). Transactions of the Royal Entomol. Soc. of London 95 (Part
6): $263-294$.

22. JOHNSON, G.D. and M.S. MULLA. 1982. An aquatic macrophyte affecting nuisance chironomid midges in a warm water lake. Environmental Ent. 12:266269.

23. MASON, P.G. 1978. A biosystematic study of larval and pupal Chironomini (Diptera: Chironomidae) from the North and South Saskatchewan Rivers. M. Sc. Thesis, University of Saskatchewan. Saskatoon. 456 pp.

24. - 1983. Systematics and ecology of Chironomidae (Diptera) associated with Tobin Lake reservoir and the Saskatchewan River. Ph. D. Thesis, University of Saskatchewan, Saskatoon. 771 pp.

25. - 1986. Four new species of the Crytochironomus fulvus (Johannsen) species complex (Diptera: Chironomidae). Entomoligicae Scandinavica 16:399-413.

26. MASON, P.G. and D.M. LEHMKUHL. 1983. Effects of the Squaw Rapids hydroelectric development on Saskatchewan River Chironomidae (Diptera). Memoirs of the Amer. Entomol. Soc. 34:187-210.

27. 1985 . Origin and distribution of the Chironomidae (Diptera) from the Saskatchewan River, Saskatchewan, Canada. Can. J. of Zool. 63:876-882.

28. MORGAN, M.J. 1949. The metamorphosis and ecology of some aspects of Tanypodinae (Diptera: Chironomidae). Entomol. Monthly Magazine 85:119-126.

29. MORRILL, P.K. 1988. Disturbance of pond Chironomidae communities by deltamethrin insecticide. M. Sc. Thesis, University of Saskatchewan, Saskatoon. $126 \mathrm{pp}$.

30. OLIVER, D.R. 1971. life history of the chironomidae. Ann. Review of Ent. 16:211-230.

31.—. 1981. Chapter 29. Chironomidae. Pp. 423-458 in McAlpine, J.F., B.V. Peterson, G.E. Shewell. H.J. Teskey, J.R. Vockeroth and D.M. Wood, (editors). Manual of Nearctic Diptera Vol. 1. Research Branch, Agriculture Canada. Monograph No. 27, 674 pp.

32. OLIVER , D.R. and M.E. ROUSSEL. 1983. The genera of larval midges of Canada (Diptera: Chironomidae). The Insect and Arachnids of Canada. Part $\Pi$. Ag. Can. Publ. 1746, 263 pp. 
PARKER, D.W. 1985. Biosystematics of Chironomidae inhabiting selected prairie ponds in Saskatchewan. M. Sc. Thesis, University of Saskatchewan, Saskatoon. $258 \mathrm{pp}$.

34.PATERSON, C.G. and C.J. CAMERON. 1982. Seasonal dynamics and ecological strategies of the pitcher plant chironomids Metriconemus nabi Coq. (Diptera: Chironomidae) in southwestern New Brunswick. Can.J. of Zool. 60:3075-3083.

35.PINDER, L.C.V. 1989. 1. The adult males of Chironomidae (Diptera) of the Holarctic region. Introduction, in Wiederholm, T. (editor), The adult males of Chironomidae (Diptera) of the Holarctic region! keys and diagnoses. Entomologica Scandinavica, Supplement 34:5-10.

36. REMPEL, J.G. 1936. The life history and morphology of Chironomus hyperboreus. $J$. of the Biological Board of Canada. 2:209-221.

37.ROBACK, S.S. 1971. The subfamily Tanypodinae in North America. Monographs of the Academy of Natural Science, Philadelphia. No. 17, 410 pp.

38.ROSENBERG, D.M. and A.P. WIENS. 1976. Community and species responses of Chironomidae (Diptera) to contamination of fresh waters by crude oil and petroleum products with special reference to the Trail River, North West Territories. $J$. of the Fisheries Res. Board of Canada. 33:1955-1963.

39. SAETHER, O.A. 1977. Female genitalia in Chironomidae and other Nematocera: morphology, phylogenies, keys. Bull. of the Fisheries Res. Board of Canada 197, 209 pp.

40. - 1980. A glossary of terminology of Chironomidae. Entomologica Scandinavica. Supplement. 14, 50 pp.

41.STEFFAN, A.W. 1965. On the epizoic associations of Chironomidae (Diptera) and their phyletic relationships. Pp. 77-78 in Proc. of the 12th International Congress of Ent., London 1964.

42.SWANSON, S.M. 1978. Ecology and production of macrobenthos in Waldsea Lake, Saskatchewan, with emphasis on Cricotopus ornatus (Diptera: Chironomidae). M. Sc. Thesis, University of Saskatchewan, Saskatoon. 238 pp.

43. SYRJAMAKI, J. 1965. Laboratory studies on the swarming behaviour of Chironomus strenzki Fittkau in litt. (Diptera, Chironomidae). I. Mechanisms of swarming and mating. Annales zoologicifennici 4:19-28.

44. WALSHE, B.M. 1951. The feeding habits of certain chironomid larvae (subfamily Tendipedidae). Proc. of the Zoological Soc. of London 121:63-79.

45. WARWICK, W. F. 1985. Morphological abnormalities in Chironomidae (Diptera) larvae as measures of toxic stress in freshwater ecosystems: indexing antennal deformities in Chironomus Meigen. Can.J. of Fisheries and Aquatic Sci. 42:18811914.

46. WARWICK, W.F. and N.A. TISDALE. 1988. Morphological deformities in Chironomus, Cryptochironomus and Procladius (Diptera: Chironomidae) from two differentially stressed sites in Tobin Lake, Saskatchewan. Can. J. of Fisheries and Aquatic Sci. 45:1123-1144.

47. WIEDERHOLM, T. (Editor). 1983. Chironomidae (Diptera) of the Holarctic region. Keys and Diagnoses. Part 1. Larvae. Entomologica Scandinavica, Supplement 19, 457 pp.

48. - 1986. Chironomidae (Diptera) of the Holarctic region. Keys and Diagnoses. Part 1. Pupae. Entomologica Scandinavica, Supplement 28, 492 pp.

49. 1989. Chironomidae (Diptera) of the Holarctic region. Keys and diagnoses. Part 3. Adult males. Entomologica Scandinavica, Supplement 34, 532 pp.

50. WRUBLESKI, D. A. 1987. Chironomidae (Diptera) of peatlands and marshes in Canada. Memoirs of the Entomological Soc. of Canada 140:141-161.

51. YOSHIMATSU, H. 1967. Feeding habits of the larvae of Chironomus dorsalis. Biology Institute Faculty of Liberal Arts Yamaguchi University, 115-125. 
Table 1. Chironomidae Known to Occur in Saskatchewan

Tanypodinae

Pentaneurini

Ablabesmyia (Ablabesmyia) monilis (Linnaeus)

+ Ablabesmyia (Karelia) illinoense (Malloch)

+ Ablabesmyia (Karelia) pulchripennis (Lundbeck)

* Conchapelopia (Conchapelopia) telema Roback

+ Derotanypus alaskensis (Malloch)

* Hayesomyia senata (Walley)

Procladiini

* Rheopelopia sp.

+ Procladius (Holotanypus) sp.

* Procladius (Procladius) denticulatus Sublette

* Procladius (Procaldius) freemani Sublette

* Procladius (Psilotanypus) bellus (Loew)

+ Procladius (Psilotanypus) nietus Roback

Psectrotanypus (Derotanypus) alaskensis (Malloch)

+ Psectrotanypus (Psectrotanypus) dyari (Coquillet)

Diamesinae

*+Tanypus (Tanypus) punctipennis Meigen

Diamesini

* Diamesa cineralla Meigen

* Potthastia longimana Keiffer

Protanypini

+Prolanypus sp.

Chironominae

Chironomini

* Chernovkskiia amphitrite (Townes)

+ Chironomus (Camptochironomus) tentans (Fabricius)

Chironomus (Chaetolabis) atroviridis (Townes)

Chironomus (Chaetolabis) sp.

+ Chironomus (Chironomus) atrella Townes

* Chironomus (Chironomus) anthracinus Zetterstedt

* Chironomus (Chironomus) decorus Johannsen

*+ Chironomus (Chironomus) plumosus (Linnaeus)

* Chironomus (Chironomus) staegeri (Lundstroem)

+ Chironomus (Chironomus) riparius Meigen

+ Cladopelma viridulus (Linnaeus)

* Cladopelma sp.

* Cryptochironomus conus Mason

* Cryptochironomus curryi Mason

* + Cryptochironomus digitatus Malloch

* Cryptochironomus eminentia Mason

* Cryptochironomus fulvus Johannsen

* Cryptochironomus ramus Mason

* Cryptochironomus scimitarus (Townes)

* Cryptochironomus stylifera Johannsen

* Cryptotendipes darbyi Sublette

Cryptotendipes casuaris (Townes)

* Cyphomella gibbera Saether

* Demicryptochironomus sp.

*+Dicrotendipes nervosus Staeger

+ Einfeldia pagana Meigen

* + Endochironomus nigricans Johannsen

+ Glypotendipes (Phytotendipes) barbipes (Staeger)

+ Glypotendipes (Phytotendipes) lobiferus (Say)

* Glypotendipes (Phytotendipes) paripes (Edwards) 
+ Glyoptendipes sp.

* Harnischia curtilamellata (Malloch)

* Microtendipes caducus Townes

* Microtendipes pedellus (De Geer)

* Nilothauma babiyi (Rempel)

* Parachironomus abortivus (Malloch)

* Parachironomus frequens (Johannsen)

Parachironomus tenuicaudatus (Malloch)

* Paracladopemla nereis (Townes)

* Paracladopemla winnelli Jackson

* Paralauterborniella nigrohalterale (Malloch)

* Paratendipes albimanus (Meigen)

* Phaenopsectra obediens (Johannsen)

* Polypedilum (Polypedilum) sp. nr. aviceps Townes

* Polypedilum (Polypedilum) convictum (Walker)

* Polypedilum (Polypedilum) fallax (Johannsen)

* Polypedilum (Polypedilum) illinoense (Malloch)

* Polypedilum (Polypedilum) laetum (Meigen)

* Polypedilum (Polypedilum) obtusum Townes

* Polypedilum (Tripodura) digitifer Townes

* Polypedilum (Tripodura) scalaenum (Schrank)

* Robackia claviger (Townes)

* Robackia demeijerei (Kruseman)

* Saetheria tylus Jackson

* Stenochironomus hilarus (Walker)

* Xenochironomus (Anceus) scopulus Townes

* Xenochironomus (Xenochironomus) xenolabis (Kieffer)

Tanytarsini

* Cladotanytarsus sp.

* Constempellina sp.

+ Corynocera sp.

* Micropsectra nigripila (Johannsen)

* Micropsectra dives (Johannsen)

* Micropsectra polits (Malloch)

* Paratanytarsus confusus Palmen

* Paratanytarsus laccophilus (Edwards)

* Rheotanytarsus exiguus (Johannsen)

+ Stempellina sp.

* Stempellina sp.

* Tanytarsus glabrescens Edwards

* Tanytarsus guerlus Roback

Orthcladiinae

+ Acricolopus senex (Johannsen)

* Cardiocladius sp.

* Corynoneura celeripes Winnertz

* Corynoneura sp. nr. taris Roback

* Cricotopus (Cricotopus) bicintus (Meigen)

* Cricotopus (Cricotopus) curtuss Jirvenjo

* Cricotopus (Cricotopus) politus (Coquillett)

* Cricotopus (Cricotopus) slossonae Malloch

* Cricotopus (Cricotopus) triannulatus (Macquart)

* Cricolopus (Cricolopus) sp. nr. tremulus (Linnaeus)

* Cricotopus (Cricotopus) trifascia Edwards

* Cricolopus (Cricolopus) sp.

* Cricotupus (Isocladius) intersectus (Staeger)

* Cricotupus (Isocladius) ornatus (Meigen)

* Cricotupus (Isocladius) sylvestris (Fabricius)

* Epoicocladius sp. 
* Eukiefferiella sp.

+ Heterotanytarsus sp.

*+Hydrobaenus sp.

+ Limnophyes sp.

* Nanocladius (Nanocladius) anderseni Saether

* Nanocladius (Nanocladius) crassocornis Saether

* Nanocladius (Nanocladius) spiniplenus Saether

* Ortholadius (Euorocladius) rivicola Kieffer

* Orthcladius (Euorocladius) ?rivicola Kieffer

* Orthocladius (Orthocladius) carlatus Roback

* Orthocladius (Orthocladius) mallochi Kieffer

* Orthocladius (Orthocladius)nigritus Malloch

* Orthocladius (Orthocladius) obrumbat us Johannsen

* Orthocladius (Orthocladius) robacki Soponis

* Orthocladius (Orthocladius) sp.

* Parakiefferiella (Parakiefferiella) tortulata Saether

* Parametriocnemus sp.

*+Psectrocladius (Allosectrocladius) flavus (Johannsen)

* Psectrocladius (Psectrocaldius) simulans (Johannsen)

* Pseudosmittia sp.

* Synorthocladius semivirens (Kieffer)

* Thienemanniella cf. xena Roback

* Tvetenia vitracies (Saether)

* Found in flowing water

+ Found in still water

Within the cells of the tiniest algae, behind the walls of the green leaf, everywhere that the unique compound chlorophyll occurs, the sun's power is held and transformed. Every living thing has been built from the products of this silent, unassuming industry. Braun and Cavagnaro. 1971. Living Water. American Wes, ? alo Alto, CA. 